\title{
Environmental Efficiency Evaluation of Coastal Tourism Development in Taiwan
}

\author{
Shu-Wei Huang, Hsing-Fu Kuo, Hsiu-I Hsieh, and Ting-Hsuan Chen
}

\begin{abstract}
In recent years, tourism has become the industry which lots of local governments promoted actively in Taiwan. Taiwan belongs to the island so that it has the abundant coastal natural resources that coastal tourism has become a major tourism development. However, coastal areas are mostly within environmentally sensitive areas, when investment and promotion of the tourism development will impact the natural environment, so it is an important topic to discuss.

This study attempts to research the extent of the environmental benefits of promoting tourism development actively through data envelopment analysis (Data Envelopment Analysis, DEA) by the view of land development and landscape ecology.
\end{abstract}

Index Terms-Coastal tourism, environmental efficiency, data envelopment analysis.

\section{INTRODUCTION}

In recent years, tourism development has become the main promoting policy for industrial development in Taiwan. However, tourism development need develop the land often that resulting in the destruction of environmental resources, or because of a large number of tourists visiting lead to a conflict between environmental maintenance. Therefore, how to achieve a balance between development and environment protection in tourism is an important subject of tourism development in the future. In particular, the coast area of Taiwan Islands where the tourism industry development prosperously have rich natural resources, but their environment are also the most fragile and sensitive area. Thus at the time for tourism development and planning, it should consider the environmental characteristics of the islands coast to promote sustainable development strategies.

Taiwan is surrounded by the sea so that it is plentiful of the coast resources, and thus isolated islands under the closed ecosystem form of a unique landscape. As leisure tourism drawing attention in recent years, the tourism industry develop vigorously recently, and therefore Taiwan's coast is the diverse recreation place where can provide the value of sightseeing. However, the island is narrow and lots of coastal areas are environmentally sensitive so that coastal tourism and recreation resources of the environment development will

Manuscript received January 30, 2015; revised May 13, 2015.

Shu-Wei Huang, Hsiu-I Hsieh, and Ting-Hsuan Chen are with the Department of Environmental and Cultural Resources, National Hsinchu University of Education, Hsinchu City, Taiwan (e-mail: upshuwei@mail.nhcue.edu.tw, nancy2432730@gmail.com, today8213@gmail.com).

Hsing-Fu Kuo is with the Department of Tourism, Leisure and Hospitality Management, National Chi Nan University, Nantou, Taiwan (e-mail: luckiekuo@gmail.com). cause great impact such as vegetation, wildlife habitat, geological and topographical structure, and local culture. The coast development ignores the vulnerability of coastal environments often, and therefore sustainable management for island coast tourism has more attention recently.

In the past studies, although some of them seek to sustainable index of islands tourism development, others are related to low carbon tourism island, however, the research on analysis and evaluation for the tourism development impact on the coastal environment are relatively lack. Especially in the current rapid development of islands coastal area, and the coastal activities occurring frequently that construct a complete strategy to promote sustainable tourism development is a very important issue.

Based on the above reasons, this study mainly focuses on exploring the environmental efficiency evaluation on tourism development. First, constructing the environmental efficiency evaluation indicators for coastal tourism development area, and using Data Envelopment Analysis (DEA) to explore the environmental benefits of tourism development. The result also can be the spatial strategies references for land use, disaster prevention and transportation planning in the future.

\section{THE RESEARCH AND CHARACTERISTIC OF COASTAL TOURISM}

\section{A. The Characteristic of Island and Coastal Tourism}

Islands always have their individual characteristic because of the special location and environment. Vulnerability and isolation are the main characteristics of the island. The isolation of the ecosystem causes the fragility of itself and the high rate of endemic species. It is very important to understand the vulnerability of islands because the ecosystem will not easy to repair once the system lose its balance by outside species [1]. Besides, the isolation of the island often produces its unique culture and living style which are attractive and benefit for tourism development [2]. Furthermore, the environmental carrying capacity, islands tourism development is connected with the community participation, local political environment, and special interest activities [3].

\section{B. The Research of Coastal Tourism}

In current study about the development of island tourism, it often explored the connotation about the development of island tourism from environmental, economic, social and cultural as well as political aspects. In environmental aspects, it discussed the topics about the use of natural resources, environmental protection, the treatment of waste and sewage and the use of renewable energy; in economic aspect, the 
tourism industry not only provided the contribution to local economy but also the job opportunities and income benefits and assessed the economic generated impact of seasonal tourism for the island region; in social cultural aspect, it focused on the preservation of local culture, the impacts on life to local residents and the attention of residents; in political aspect, it paid more attention on government policies and the cooperation between official and non-profit organizations.

McNamara and Gibson [4] explored the coastal environment and sustainable development by profiling 536 tourist accommodation facilities of the Australian east coastline. It profiled the self-acknowledged implementation of environmental initiatives by managers of tourist accommodation facilities along Australia's coast.

The survey results indicate poor uptake of environmental initiatives that concluded by arguing that such results are a consequence of barriers including the inheritance of older built environments and the poor communication to the managers of facilities of the benefits of implementing environmental initiatives.

Mahonyt et al. [5] pointed out that implementation of sustainable tourism is influenced by the availability and accessibility of relevant data; both as a means of progress evaluation and providing information to key stakeholders, e.g. regulators, service providers and visitors in the study of European coastal sites. Results indicated that lots of commonalities and disparities exist between the sites assessed notably in terms of data format, access and availability. Measures for consideration are proposed as a means of overcoming the operational challenges facing coastal managers and practitioners involved with promoting sustainable tourism.

Through analyzing the coastal tourism by comparing analysis Croatia with Tunisia, Rutin [6] pointed out the results about Croatia and Tunisia present two different models of coastal tourism. The Tunisian model presents continuity and stability in the amount of incoming tourists throughout the whole year, while the Croatian model is a seasonal one, with a very high peak during the summer and a minimum influx of tourists during the winter. The main reason for this difference is the Croatian colder winter; the result is high seasonal instability in the Croatian tourism industry.

Buckley [7] put forward the sustainable tourism views that the five categories responses and indicators, population, peace, prosperity, pollution and protection, were reviewed for the mainstream tourism sector worldwide in social and environmental impacts. Very few relevant publications attempted to evaluate the entire global tourism sector in terms which reflect global research in sustainable development. The main driver for improvement is regulation rather than market measures. Future research priorities include: the role of tourism in expansion of protected areas; improvement in environmental accounting techniques; and the effects of individual perceptions of responsibility in addressing climate change.

Yang et al. [8] researched on geospatially analyzes beach availability for global recreational tourism management with focus on a case study of Jekyll Island off the coast of Georgia, USA. Such information allowed tourists to choose beach areas suitable for recreational or ecological activities so that manage the coastal tourism. Dry beach availability also assists coastal restoration managers. The results predicted shoreline changes and dry beach access while promoting minimal impacts by tourists on fragile coastal dune ecosystems.

Monavari et al. [9] used Fuzzy and Boolean logics to select areas with tourism potentiality and combined the Integrated Coastal Tourism Zone Management (ICTZM) framework to provide in the form of a conceptual model that regarded simultaneously social, cultural and economical criteria along with spatial planning in terms of environmental capabilities to overcome the various problems. Results revealed that the main strategy to implement the sustainable coastal tourism in the study area should be based on a conservative approach and after the improvement in the conditions; the development and construction strategy can be executed in the coastal zone.

Gladstone et al. [10] presented that the Gulf and Red Sea possess diverse coastal and marine environments that support rapidly expanding mass tourism, but there was no analysis of the tourism-related literature or recent analysis of environmental risks impacts. A full account of tourism's environmental impacts was constrained by limited tourism data, confounding of impacts with other coastal developments, lack of baseline information, shifting baselines, and fragmentation of research across disciplines.

Ong and Smith [11] researched on managing sustainable coastal tourism in emerging destinations that compared the sustainability practice outcomes according to differing stakeholders and their perceptions of sustainability. The research identified gaps between policies and their implementation where the intent is to highlight those aspects of contemporary resort growth that need greater attention by policy makers and planners. It were found that there was alignment between the perceptions and the reality of sustainable tourism practices within and across the stakeholder groups, and pointed to the challenges ahead for all stakeholders in managing coastal destinations sustainably also.

\section{The Concept of Environment Efficiency}

Schaltegger and Sturm [12] proposed the concept of environmental efficiency what defined as the ratio relationship of the increasing value and the increasing environmental impact. World Business Council for Sustainable Development (WBCSD) in order to combine the production process and sustainable development that described environmental efficiency as "while progressively reducing ecological impacts and resource intensity throughout the life cycle, to a level at least in line with the Earth's estimated carrying capacity within being achieved by the delivery of competitively priced goods and services that satisfy human needs and bring quality of life." in 1992. Thus, the initial sense of environmental efficiency refered to economic value of the ratio of the additional environmental stress indicators, emphasis on increasing the economic value lies in the largest efficiency of the production output. In short, the corporate vision about environmental efficiency was the pursuit of economic value maximization, and environmental impact was minimized.

$$
\text { Environmental Efficiency }=\frac{\text { Economic value added }}{\text { Environmental pressures }}
$$


There were seven elements established by WBCSD about environmental efficiency. 1) Reduce material intensity. 2) Reduce energy intensity. 3) Maximize use of renewable resources. 4) Reduce dispersion of toxic substances. 5) Increase service intensity 6) Improve recyclability. 7) Extend product durability. Environmental efficiency applied to business units at first what on behalf of the proportion of the sum of the environmental pressure caused by the enterprise or industry and the total value of goods and services. The advantage was it can give consideration to energy consumption and ecological quality simultaneously under the modern society with population growth and urbanization [13]. On the other hand, assessing the high and low values of the efficiency by the input and output indicators was able to represent the area meets the sustainable development or not, but it was not easy to quantify the assessment of the interaction between the various indicators. In addition, it was hard to sum up the results from the different indicators on policy evaluation.

Therefore, some scholars have pointed out that DEA can conduct a comprehensive assessment on different type of data about ecological, economic and physical environment, and provide clear and significant standardization results [13], [14]. Although sustainable development has been proposed for some time, but its importance has not decreased, many scholars believed that environmental efficiency and sustainable development was closely linked [15].

Cha et al. [16] pointed out environmental efficiency was from the global sustainable development issues, and was an important concept to assess sustainability. Its characteristic was from micro-scale improvement on production technology and environmental quality to macroscopic target of sustainable development [17]-[21]. Recent studies also considered assessing the sustainability or sustainable development as emerging tools.

\section{METHOD AND INDICATOR}

\section{A. The Application of Data Envelopment Analysis}

The data envelopment analysis (DEA) is a multivariate analysis technique for relative efficiency, which can evaluate the decision-making unit with multiple inputs and multiple outputs [22]. As a characteristic of DEA, no prior knowledge of the production function between the input and output attribute data is required, and no relative weight needs to be set for the attribute data. It is a nonparametric mathematical programming model, and its economic significance indicates the boundary consisting of all of the best possible points. In the concept of the Pareto optimum, the ex post data are used to assess the efficiency. The relative efficiency is assessed by the approach of establishing an efficiency frontier [23].

DEA approach is able to assess indicators of different types and data patterns comprehensively and is widely used in economic science, agricultural economics, public economics, financial economics, and overall economic policy. DEA is also considered an appropriate analysis method for many studies that are related to environmental efficiency [24], [25]. Therefore, considering the characteristics of complexity and development for urban areas and the advantages of DEA, this analytical method was applied for the efficiency assessment in this study.

The original idea behind DEA was to provide a methodology whereby, within a set of comparable decision making units (DMUs), those exhibiting best practice could be identified, and would form an efficient frontier [26]. The analysis in this study was used to search for the minimal inputting environmental impact cost and natural resource depletion with the current output level. Therefore, the input-oriented model [27] was used in this study for the efficiency assessment.

$$
\begin{gathered}
e_{j}=\max \frac{\sum_{r=1}^{s} u_{r} y_{r j}}{\sum_{i=1}^{m} v_{i} x_{i j}} \\
\text { s.t. } \frac{\sum_{r=1}^{s} u_{r} y_{r j}}{\sum_{i=1}^{m} v_{i} x_{i j}} \leq 1 \\
0<\varepsilon \leq u_{r}, v_{i} ; \quad i=1, \ldots, m ; r=1, \ldots, s ; j=1, \ldots, n
\end{gathered}
$$

where $x_{i j}$ is the $i$ input indicator value of $j$ DUM; $y_{r j}$ is the $\mathrm{r}$ output indicator value of $j \mathrm{DUM} ; u_{r}$ and $v_{i}$ is the weight of output and input indicator; $e_{j}$ is the relative efficiency value of $j \mathrm{DMU} ; \varepsilon$ is a non-archimedian value designed to enforce strict positivity on the variables.

\section{B. Input and Output Indicators}

In the process of efficiency evaluation, the selection of representative indicators as the input and output is both very important and difficult [28]. Due to the complexity of reservoir catchment area, the factors of inputs and outputs between the socio-economy and the environment are often difficult to define.

The major considerations for selecting the indicators are: the indicators related to sustainable coastal tourism development, the indicators for the environmental impact of tourism industry and activity development, the characteristics of the spatial scale in a town, and the representation and usability of data analysis.

\section{CASE STUdY}

\section{A. Study Area}

The coast towns were selected as the area for empirical research in this study; the scope and geographic location are shown in Fig. 1.

For selecting the spatial analysis units, four basic principles were developed in this study, including the significance of a standard measurement for efficiency assessment and the practical applicability of planning, which reflect the 
development characteristics of the area for empirical research and meet the restrictions for the number of units for evaluation and decision making. A total of 93 coast towns were considered as the smallest decision-making units (DMUs) of analysis (Fig. 2).

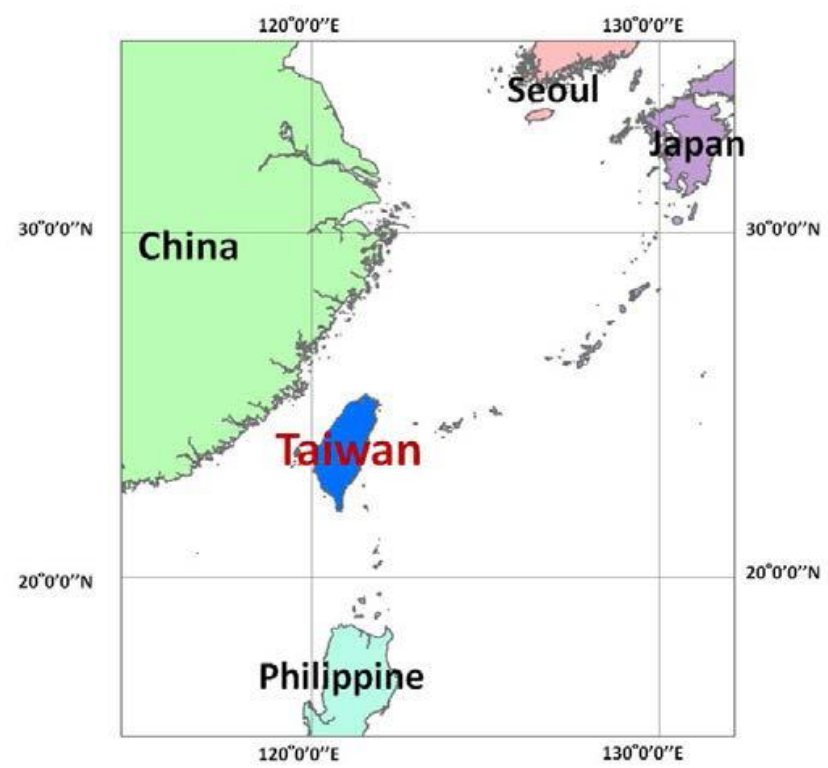

Fig. 1. Location of the research site.

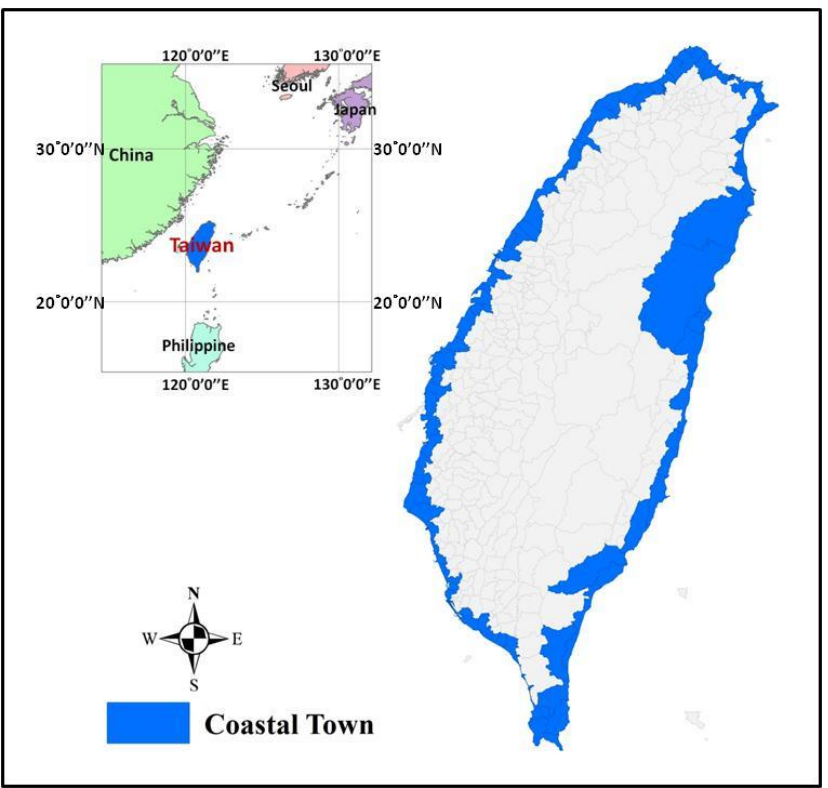

Fig. 2. The relative locations of analysis units.

\section{B. The Spacial Distribution of Input and Output Indicators}

The outputs are the value of tourism industry, the area of building area, population, and income. The inputs are the area of habitat, the diversity of habitat, waste clear up per person per day, and power consumption per person.

In the aspect of information obtained, since Taiwan's value of tourism industry survey once every five years, the recent survey was in 2011. Therefore, the data of input and output indicators are both the 2011 survey data except building area data for 2010.

All the data of indicators had divided into four levels by quartile, and the spatial distribution of output and input indicators were shown in Fig. 3 and Fig. 4.
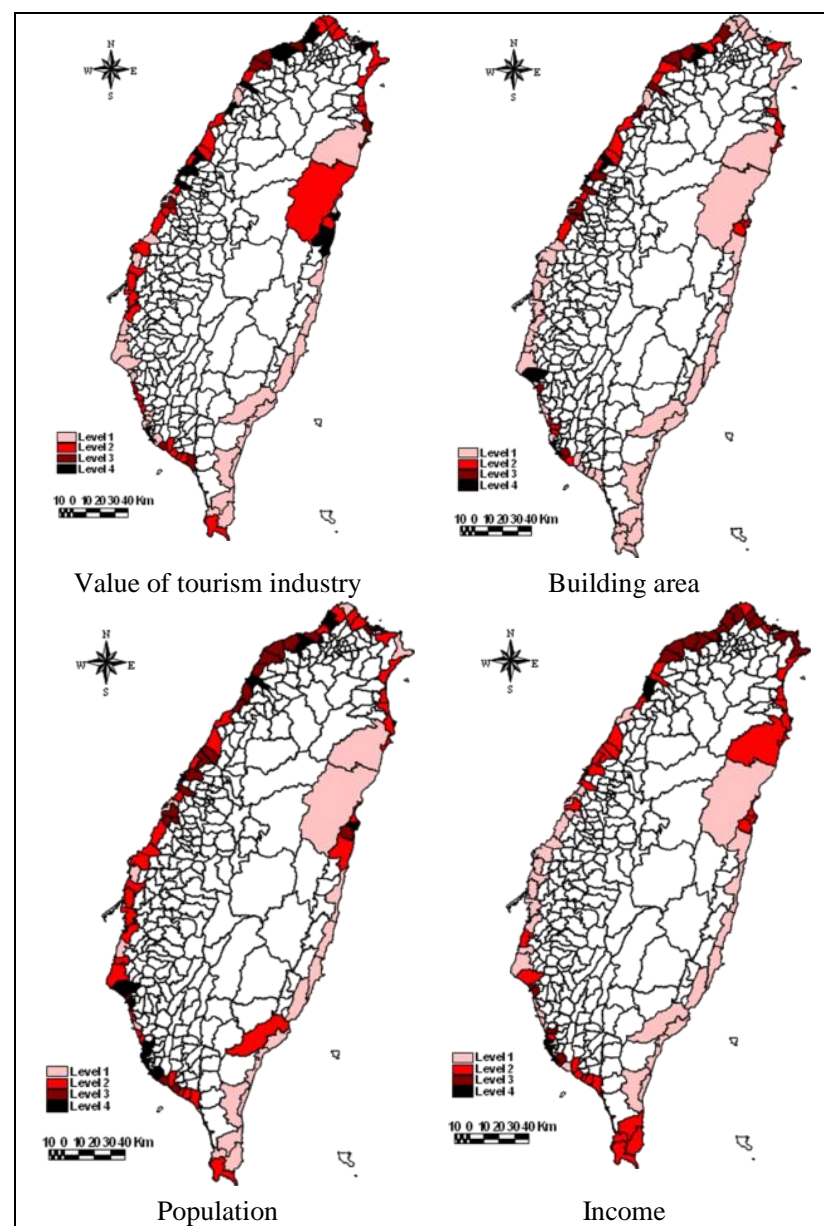

Fig. 3. The special distribution of the output indicators.
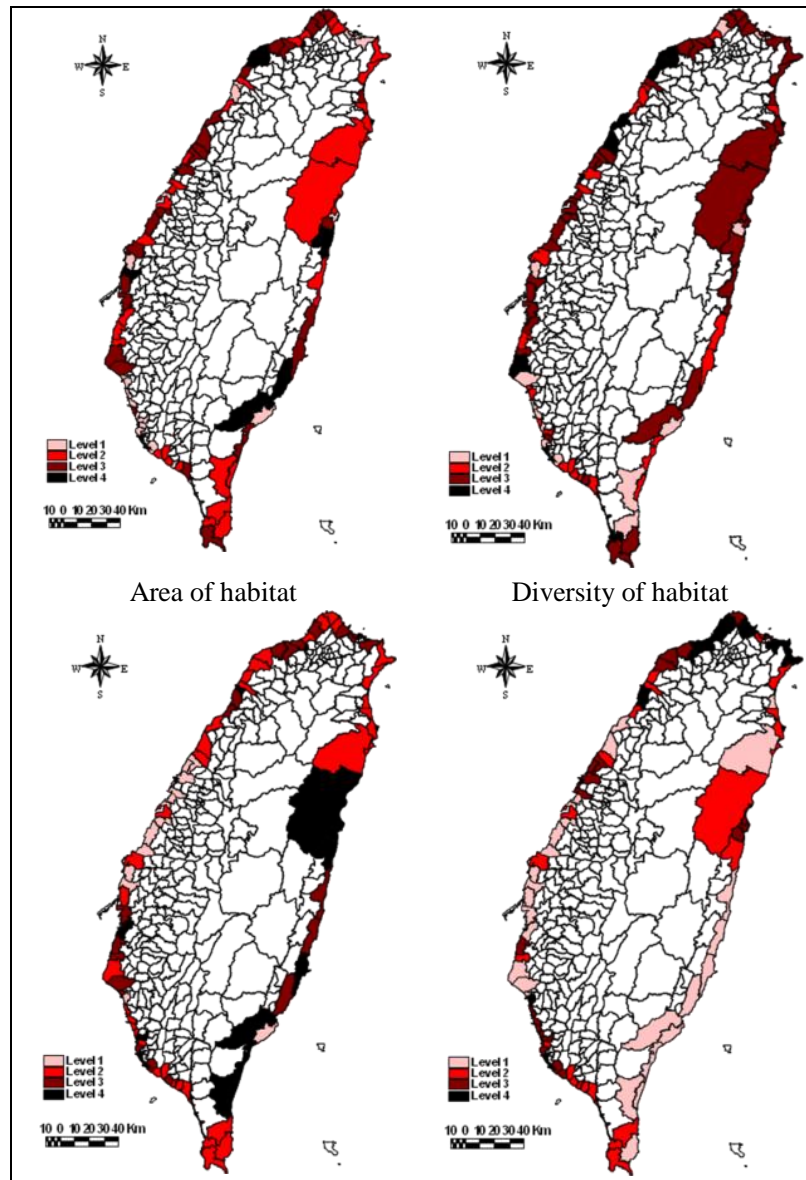

Diversity of habitat

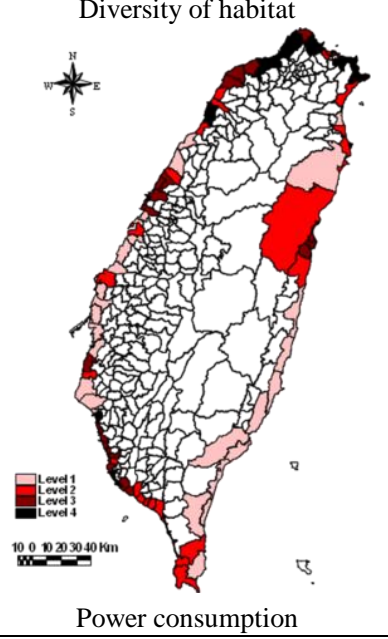

Waste clear up

Power consumption 


\section{Scores of Environment Efficiency}

The average efficiency value of the 93 coast towns was $88.93 \%$, with a maximum efficiency value of $100 \%$ and a minimum of $39.30 \%$. A total of 51 coast towns had an efficiency of $100 \%$, and 26 coast towns were between $75 \%$ and $100 \%$ (Fig. 5).

The results showed that most of the coastal towns for the environmental benefits arising from the tourism development are good generally. On the spatial distribution of benefits, coastal towns with high efficiency values were more concentrated in the western Taiwan because the input value in western Taiwan was higher, while the value of output was higher also. In contrast, it was high value of the input, but less output value in eastern Taiwan that impact the effectiveness on the entire environment development.

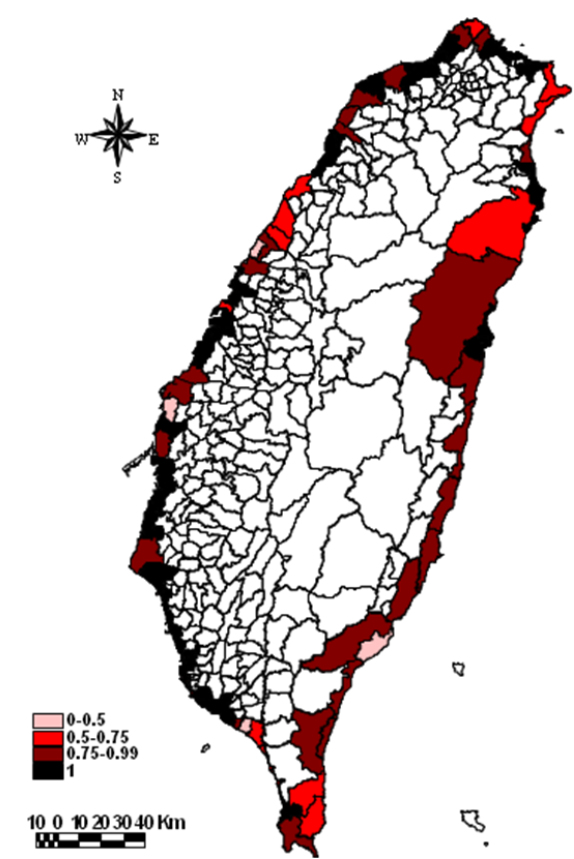

Fig. 5. The distribution of the scores of environment efficiency.

\section{RESUlT AND CONCLUSION}

From the above analysis showed that promote the tourism development would be related to the maintenance of the environment. Through the operation of this study could analyze the degree of effectiveness between the tourism development and environmental maintenance quickly. There were increasing emphasis on environmental issues in Taiwan in recent years; on the whole, on the assessment of environmental benefits for coastal tourism development, majority of the region has reached the standard of a benefit, and the situation in western Taiwan was better than eastern region. However, there are 16 coastal towns where benefits were lower than $75 \%$ that most of these areas were with sparse residential populations, low income, and the heavy energy consumption. It should pay more attention to the impact of these indicators arising when promoting tourism development in Taiwan's coast in the future.

Coast usually is one of the main tourism development areas as its diversity natural resources. However, the tourism development usually came with some bad impacts for the ecological and social environment. For example, traditional living style may be changed to satisfy tourist demand; special ecosystem and culture in coast area may disappear without suitable planning and management. In the end, the island may lose its attractive characteristics for the tourist. Thus, it is crucial to make a coast sustainable development plan. To ensure the natural and social environment are also maintained under sustainable economy development.

\section{REFERENCES}

[1] S. Bass and B. Dalal-Clayton, Small Island States and Sustainable Development: Strategic Issues and Experience, London: International Institute for Environment and Development, 1995.

[2] R. Scheyvens and J. Momsen, "Tourism in small island states: From vulnerability to strengths," Journal of Sustainable Tourism, vol. 16, no. 5, pp. 491-510, 2008.

[3] C. C. Lim and C. Cooper, "Beyond sustainability: Optimising island tourism development," International Journal of Tourism Research, vol. 11 , no. 1 , pp. 89-103, 2009.

[4] K. E. McNamara and C. Gibson, "Environmental sustainability in practice? A Macro-scale profile of tourist accommodation facilities in Australia's coastal zone," Journal of Sustainable Tourism, vol. 16, no. 1, pp. 85-100, 2008.

[5] C. O. Mahonyt, M. Ferreiraj, Y. Fernandez-Palacios, V. Cumminsf, and R. Harounoo, "Data availability and accessibility for sustainable tourism: An assessment involving different European coastal tourism destinations," Journal of Coastal Research, vol. 56, pp. 1135-1139, 2009.

[6] J. Rutin, "Coastal tourism: A comparative study between Croatia and Tunisia, tourism geographies: An international journal of tourism space," Place and Environment, vol. 12, no. 2, pp. 264-277, 2010.

[7] R. Buckley, "Sustainable tourism: Research and reality," Annals of Tourism Research, vol. 39, no. 2, pp. 528-546, 2012.

[8] B. Yang, M. Madden, J. Kim, and T. R. Jordan, "Geospatial analysis of Barrier Island beach availability to tourists," Tourism Management, vol. 33, pp. 840-854, 2012.

[9] M. Monavari, M. H. Abed, A. Karbassi, P. Farshchi, and Z. Abedi, "Integrated coastal tourism zone management (ICTZM) as a basis for sustainable development of the south coastline of the Caspian Sea Indian," Journal of Geo-Marine Sciences, vol. 42, no. 5, pp. 635-646, 2013.

[10] W. Gladstone, B. Curley, and M. R. Shokri, "Environmental impacts of tourism in the Gulf and the Red Sea," Marine Pollution Bulletin, vol. 72, pp. 375-388, 2013

[11] L. T. J. Ong and R. A. Smith, "Perception and reality of managing sustainable coastal tourism in emerging destinations: The case of Sihanoukville, Cambodia," Journal of Sustainable Tourism, vol. 22, no. 2, pp. 256-278, 2014.

[12] S. Schaltegger and A. Sturm, "Ökologische rationalität," Die Unternehmung, vol. 4, no. 90, pp. 273-290, 1990.

[13] G. Huppes and M. Ishikawa, "A framework for quantified eco-efficiency analysis," Journal of Industrial Ecology, vol. 9, no. 4, pp. 25-41, 2005.

[14] A. P. Barnes, "Does multi-functionality affect technical efficiency? A non-parametric analysis of the Scottish dairy industry," Journal of Environmental Management, vol. 80, no. 4, pp. 287-294, 2006.

[15] J. Seppala, M. Melanen, I. Maenpaa, S. Koskela, J. Tenhunen, and M R. Hiltunen, "How can the eco-efficiency of a region be measured and monitored?," Journal of Industrial Ecology, vol. 9, no. 4, pp. 117-130, 2005.

[16] K. Cha, S. Lim, and T. Hur, "Eco-efficiency approach for global warming in the context of kyoto mechanism," Ecological Economics, vol. 67, no. 2, pp. 274-280, 2008.

[17] G. Huppes, "Eco-efficiency: From focused technical tools to reflective sustainability analysis," Ecological Economics, vol. 68, no. 6, pp. $1572-1574,2009$

[18] G. Huppes and M. Ishikawa, "Eco-efficiency guiding micro-level actions towards sustainability: Ten basic steps for analysis," Ecological Economics, vol. 68, no. 6, pp. 1687-1700, 2009.

[19] R. K. Singh, H. R Murty, S. K. Gupta, and A. K. Dikshit, "An overview of sustainability assessment methodologies," Ecological Indicators, vol. 9, no. 2, pp. 189-212, 2009.

[20] J. Sorvari, R. Antikainen, M. L. Kosola, P. Hokkanen, and T. Haavisto, "Eco-efficiency in contaminated land management in Finland Barriers and development needs," Journal of Environmental Management, vol. 90, no. 5, pp. 1715-1727, 2009. 
[21] D. Z. Li, E. C. M. Hui, B. Y. P Leung, Q. M. Li, and X. Xu, "A methodology for eco-efficiency evaluation of residential development at city level," Building and Environment, vol. 45, no. 3, pp. 566-573, 2010.

[22] E. Thanassoulis, "A comparison of regression-analysis and data envelopment analysis as alternative methods for performance assessments," Journal of the Operational Research Society, vol. 44, no. 11 , pp. 1129-1144, 1993

[23] M. Bevilacqua and M. Braglia, "Environmental efficiency analysis for ENI oil refineries," Journal of Cleaner Production, vol. 10, no. 1, pp. $85-92,2002$.

[24] T. J. D. Koeijer, G. A. A. Wossink, P. C. Struik, and J. A. Renkema, "Measuring agricultural sustainability in terms of efficiency: The case of Dutch sugar beet growers," Journal of Environment Management vol. 66, pp. 9-17, 2002.

[25] T. Kuosmanen and M. Kortelainen, "Measuring eco-efficiency of production with data envelopment analysis," Journal of Industrial Ecology, vol. 9, pp. 59-72, 2005.

[26] W. D. Cook and L. M. Seiford, "Data envelopment analysis (DEA) Thirty years on," European Journal of Operational Research, vol. 192, pp. 1-17, 2009.

[27] R. D. Banker, "Estimating most productive scale size using data envelopment analysis," European Journal of Operational Research, vol. 17 , no. 1, pp. 35-44, 1984.

[28] V. Bosetti and G. Locatelli, "A data envelopment analysis approach to the assessment of natural parks' economic efficiency and sustainability: The case of Italian national parks," Sustainable Development, vol. 14, no. 4, pp. 277-286, 2006.

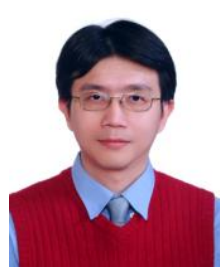

Shu-Wei Huang received the Ph.D. degree in 2008, in the Department of Urban Planning of National Cheng Kung University, Taiwan. Currently, he is an assistant professor in the Department of Environmental and Cultural Resources of National Hsinchu University of Education in Taiwan.

Assistant Prof. Huang occupies a commissioner in the Committee of Urban Design and Land Use

Development Permit and Committee of Program Advancement of Urban Renewal in Hsin-Chu City Government in Taiwan. His research interests include urban planning, spatial analysis and land use change.

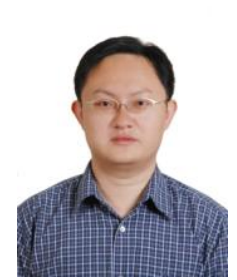

Hsing-Fu Kuo is currently an assistant professor at the Department of Tourism, Leisure and Hospitality Management, National Chi Nan University, Taiwan. His research interests include tourism management, urban and regional planning, environmental impact evaluation and land use simulation

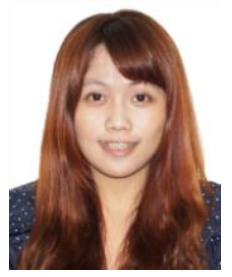

Taiwan.

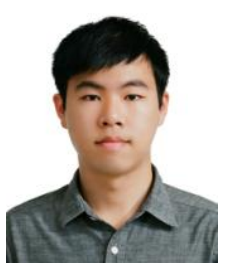

Hsiu-I Hsieh was born in Tainan City, Taiwan on July 30, 1990. She received both the M.S. and B.S.Sc. degrees in the Department of Environmental and Cultural Resources, National Hsinchu University of Education, Hsinchu City, Taiwan, from 2008 to 2014. She is now a research assistant at the Department of Environmental and Cultural Resources, National Hsinchu University of Education, Hsinchu City,

Ting-Hsuan Chen was born in Kaohsiung City, Taiwan on January 3, 1993. He is now a B.S.Sc. student at the Department of Environmental and Cultural Resources, National Hsinchu University of Education, Hsinchu City, Taiwan. 